\title{
ISO 14000 Y LA GESTIÓN MEDIO AMBIENTAL
}

\section{INTRODUCCIÓN}

ISO 14000 es un conjunto de Normas Internacionales de carácter voluntario, orientadas hacia la gestión efectiva del medio ambiente en las organizaciones.

Implica el desarrollo de requisitos concretos de los Sistemas de Gestión Ambiental, la Auditoría Ambiental, el EcoEtiquetado y el ciclo de vida de Productos, Servicios y Procesos dentro de las aspiraciones de las Organizaciones.

\section{ANTECEDENTES}

En los Estados Unidos de Norteamérica (1899) se aprobó la Primera Ley sobre el Medio Ambiente, a la cual se le denominó: “ACTA DE APROBACIÓN DE RÍOS Y PUERTOS DE 1899", también conocida como el "ACTA DE DESECHOS DE 1899”.

En 1910, se aprobó el “ACTA DE LOS INSECTICIDAS".

En 1912, se aprobó el "ACTA SOBRE EL SERVICIO DE SALUD PÚBLICA" y en 1924, fue aprobada el "ACTA DE CONTAMINACIÓN DEL PETRÓLEO".

Posteriormente, en 1955 se puso en vigencia la "PRIMERA ACTA SOBRE EL CONTROL DE LA CONTAMINACIÓN DEL AIRE”.

En el Continente Europeo, la principal indicación del efecto internacional del movimiento de protección del medio ambiente fue el nacimiento del Partido de los Verdes.
Muy pronto muchos países tenían un partido “VERDE”, cuya finalidad era promover la legislación para proteger el entorno natural.

Su poder político iba a aumentar en la década de los ochenta, ello presionó a los gobiernos para responder a un interés generalizado por la pérdida de los recursos naturales, la contaminación, la población y el impacto de tener una sociedad muy industrializada.

Debemos resaltar que el nacimiento de los "Partidos Verdes" en todo el mundo, se puede atribuir al éxito en las elecciones de 1983 del Partido Verde Alemán.

\section{LAS NACIONES UNIDAS}

Este organismo también se ha ocupado de las cuestiones medioambientales de los distintos países. Así tenemos que en 1972, se celebró la CONFERENCIADE ESTOCOLMO SOBRE EL MEDIO AMBIENTE HUMANO.

Esto condujo una serie de discusiones sobre los efectos internacionales de la contaminación y a una diversidad de opiniones relativas a la preservación del medio ambiente.

Todo ello culminó en el año 1992, con la CONFERENCIA DE LAS NACIONES UNIDAS SOBRE EL MEDIO AMBIENTE Y DESARROLLO (UNCED) celebrada en Brasil. Esta conferencia reunió a representantes de todo el mundo, a fin de firmar una serie de declaraciones. El tema principal que se discutió fue el concepto de "Desarrollo Sostenido", al mismo tiempo que se respetaba el medio ambiente, habiendo 
prometido cada país desarrollar políticas en apoyo de esta idea.

\section{BRITISH STANDARD 7750}

La BS 7750 se publicó el 6 de abril de 1992, bajo el nombre de Sistemas de Gestión Medioambientales. Esta forma fue desarrollada por el Instituto de Normalización Británico (BSI), como respuesta a la necesidad de un sistema de gestión medioambiental uniforme y proporciona a toda organización un modelo para el desarrollo de un sistema de gestión que tenga en cuenta todas las cuestiones medioambientales.

Se considera a esta Norma BS 7750 como uno de los aportes fundamentales para la creación de ISO 14000.

Debemos dejar en claro que el movimiento de protección del medio ambiente es diferente de un Sistema de Gestión Medioambiental. Sin embargo, el auge del movimiento medioambiental ha sido y es una de las principales condiciones que han conducido al desarrollo de una norma internacional para los sistemas de gestión medioambiental.

\section{LA CREACIÓN DE LA ISO 14000 - COMITE TÉCNICO 207}

A principios de la década de los noventa, la demanda industrial de una norma internacional para los sistemas de gestión del medio ambiente movió a la Organización Internacional de Normalización para la creación de un comité técnico. Su función consistía en reunir a representantes de varios países, para llegar a un consenso acerca de una norma voluntaria que pudiera ser utilizada por todos los países participantes.

En el caso de la creación de una norma internacional voluntaria para los sistemas de gestión medioambiental, el comité que se creó fue llamado Comité Técnico 207 o TC 207. Porteriormente, este comité se divide en subcomités y grupos de trabajo. Cada uno de estos grupos se especializaba en temas específicos.

La actividad del TC 207 es normalizar todos los instrumentos y sistemas dentro del sistema de gestión del medio ambiente.

\section{Los objetivos del TC 207}

Cuando se formó el TC207, se fomentaron una serie de principios de desarrollo de una norma internacional para los sistemas de gestión del medio ambiente. El objetivo global del comité técnico era llegar a definir una serie de normas básicas y uniformes que pudieran ayudar a una organización en el logro de sus objetivos de protección del medio ambiente, utilizando instrumentos y sistemas de gestión efectivos y al mismo tiempo, protegiéndose del posible impacto negativo sobre el comercio y el intercambio. El comité técnico piensa que una amplia lista de normas nacionales sólo serviría para impedir el comercio mundial. Por lo tanto, propusieron una norma internacional que favoreciese el comercio internacional.

Este objetivo general fue definido más ampliamente por diez principios que los comités utilizarían en el desarrollo de la familia de normas de la ISO 14000:

1. Gestión avanzada del medio ambiente, mediante la promoción de técnicas de gestión uniformes, efectivas y eficientes.

2. Desarrollo de normas pragmáticas y científicamente probadas para la gestión del medio ambiente que reflejen las mejoras prácticas actuales.

3. Elaborar normas de coste efectivo, que no prescriban, $y$ flexibles, a fin de 
incorporar valor añadido a las organizaciones que las utilicen.

4. Disuadir de la utilización de una norma de gestión del medio ambiente como barrera comercial.

5. Armonizar la norma internacional para los sistemas de gestión ecologistas con las normas locales y nacionales.

6. Evitar fijar niveles específicos de ejecución del trabajo, metas, objetivos, políticas o niveles de mejora.

7. Desarrollar una norma de gestión medioambiental que pueda ser utilizada por la organización interna o por una tercera parte externa con autoridad certificada.

8. Evitar las normas que pudieran requerir que una compañía tuviese que divulgar sus objetivos, políticas o proyectos al público.

9. Desarrollar normas medioambientales mediante el consenso de las partes interesadas por la adopción voluntaria de organizaciones afectadas para beneficiar todas las partes.

10. Aumentar y minimizar las normas para evitar la duplicidad y los gastos innecesarios.

\section{NORMAS DE LA SERIE ISO 14000}

A continuación, se presenta parte de la Serie ISO 14000 , indicando en cada una de ellas, el tema que comprenden:

*ISO 14001 - Sistemas de Gestión medioambiental.

Especificaciones con guías para su uso.

*ISO 14004 - Sistemas de gestión medioambiental.

Guías y principios generales. Sistemas y técnicas de soporte.

*ISO 14010 - Guías para la auditoría medioambiental.

Principios generales

*ISO 14011 - Guías para la auditoría medioambientales, procedimientos de auditoría.

Auditoría de sistemas de gestión medioambiental.

UNE ISO 14012 - Guías para la auditoría medioambiental. Criterios de calificación para auditores medioambientales.

*ISO 14013 - Programas de auditoría de la gestión medioambiental.

*ISO 14015 - Sedes de valoraciones medioambientales.

*ISO 14020 - Principios y metas de todo etiquetaje medioambiental.

*ISO 14021-Etiquetaje medioambiental Autodeclaración de reclamaciones medioambientales - Plazos y definiciones.

*ISO 14022 - Etiquetaje medioambiental - Símbolos.

*ISO 14023 - Etiquetaje medioambiental - Métodos de pruebas y ensayos.

*ISO 14024 - Etiquetaje medioambiental - Principios guía, prácticas y criterios básicos.

*ISO 14031 - Resultados de etiquetaje medioambiental -Metodología general.

*ISO 14032 - Resultados de etiquetaje medioambiental - Industrias - indicadores específicos. 
*ISO 14040 - Análisis de ciclo de vidaPrincipios generales.

*ISO 14041- Análisis de ciclo de vida Análisis inventario del ciclo de vida.

*ISO 14042 - Análisis de ciclo de vida Valoración del impacto.

*ISO 14043 - Análisis de ciclo de vida Interpretación.

*ISO 14050 - Términos y definiciones.

\section{BIBLIOGRAFÍA}

CLEMENTS, Richard. B.

1996. "Guía de las Normas ISO 14000". Barcelona, España.

INSTITUTOTECNOLÓGICODE MONTERREY 1997. "Sistemas de gestión ambiental ISO 14000". México.

MALAXECHEVARRÍA, Ángel 1998. "Auditoría ambiental". Madrid, España. 